tic reform" in higher education. According to Atagi, the budget cuts for state-owned universities may suggest that privatization can help the public universities gain freedom from cumbersome government "bureaucratic restrictions on their financial and administrative autonomy." She also proposed they can then also become "more accountable to the public, and of higher quality."

My own reading of this proposed reform is less sanguine. Even before the economic meltdown, 70 percent of Thailand's 60 million people lacked the financial means for university education. Today, a mere 14 percent of the population goes into higher education. The substantial rise in tuition fees inevitably following upon privatization will only lower this percentage even more.

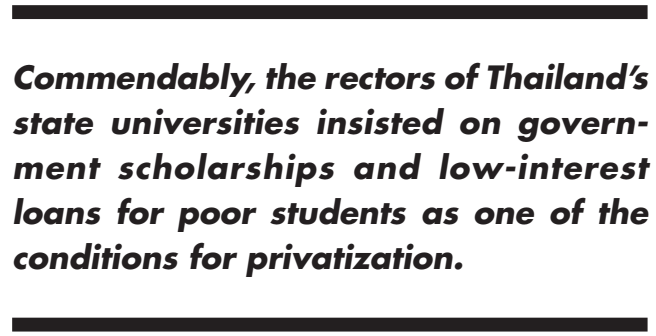

Commendably, the rectors of Thailand's state universities insisted on government scholarships and low-interest loans for poor students as one of the conditions for privatization. However, as Dr. Rapin Thongra-ar of Ramkhamhaeng University (one of Thailand's two open universities) has observed, most students needing such loans will be unable to pay them back within the present economic system.

The altruistic motives of the founding vision led many private institutions to maintain generous scholarships for financially strapped but promising students. However, in most cases they simply cannot do so to the same extent that a national system can. Private goodwill can never fully replace national commitment to the common good for the next generation. Privatization weakens that commitment.

While the government clearly needs to divest itself of certain state-owned enterprises in order to solve the present economic crisis, universities should not be grouped among these enterprises too lightly. If done carelessly, and without genuine concern for the integral development of the nation, privatization of public universities will only be another tragic example of shortterm gain and long-term loss. Unless the state universities privatize for larger reasons than the profit motive or meeting IMF paybacks, unless they preserve their mission of service to the entire population, both quality and equity will deteriorate.

\section{Mexico's Approach to Quality Assurance}

\section{Mohamed El-Khawas and Elaine El-Khawas}

Mohamed El-Khawas is professor of history at the University of the District of Columbia. Elaine El-Khawas is professor of higher education at the University of California, Los Angeles. Address: School of Education, Moore hall, UCLA, Los Angeles, CA 90095.

$\mathrm{T}$ he last decade has seen substantial growth throughout the world in higher education quality assurance systems. As one knowledgeable observer notes, more than 50 agencies now exist worldwide that have roles related to quality assessment or quality assurance. ${ }^{1}$ In most cases, these agencies have been mandated by government decrees and follow a design developed by ministry officials. Often these agencies have encountered resistance or criticism. In other instances, their approach has had to be revised extensivelyor even disbanded-after a short time.

By the late 1980s, Mexican institutions of higher education were in dire need of additional funding. The financial crisis of the 1980s caused a 50 percent decline in the purchasing power of faculty salaries, forcing many qualified academics to quit their jobs or to take on additional employment. This resulted in severe staffing problems and a deterioration in teaching conditions at a time of increasing enrollments. This led to public concern and government demands for improving the quality of higher education. With the economic recovery in the late 1980s, the government was ready to increase public expenditures on higher education but insisted on reforms and increased public accountability.

\section{Since 1989, the Mexican government has taken steps to strengthen quality assurance.}

\section{Mexico's Pluralistic Approach}

Since 1989, the Mexican government has taken steps to strengthen quality assurance. However, instead of imposing a single model, it has supported the development of different assessment mechanisms. Rather than one agency for quality assurance, for example, the country has multiple programs that are carried out by several separate organizations. The Mexican approach has been participatory, with both government and higher education involved in numerous meetings, commissions, and planning committees. 
Mexico has initiated several quality assurance approaches for its higher education system, which serves 1.3 million students. In the public sector, institutions have had some form of internal review since the early 1990s, initially through annual self-assessment and later through more detailed institutional development plans. At the same time, mechanisms for external evaluations based on external peer reviews of academic programs have also been put into place. In several professional specialties, accreditation councils have recently been established.

\section{Mexico has initiated several quality as- surance approaches for its higher edu- cation system.}

Other monitoring procedures include, for example, a statistical reporting system-designed to offer overall planning and evaluation information. Procedures have been introduced for evaluating individual academics - in both research and teaching - and standardized examinations of student knowledge and skills are being developed.

These initiatives emerged from a government decision to make quality assurance a priority, explicitly linked to modernizing and strengthening higher education. Rather than spelling out the design for quality assurance, however, the government set the process in motion by creating a national commission charged with developing a plan and getting some evaluation activities underway.

\section{New Assessment Mechanisms}

In 1989, the government created a new national body, the National Commission for the Evaluation of Higher Education (CONAEVA). This body, which included both government and university leaders, focused on three areas: institutional assessment conducted by institutions through annual self-evaluation, interinstitutional evaluation of academic programs by qualified external reviewers, and evaluation of the higher education system as a whole.

Since 1990, new actions have been taken in each of these areas. Public institutions of higher education, especially the National University of Mexico (UNAM) and the Metropolitan University (UAM), have gained experience with producing annual institutional self-assessment reports. These reports identify strengths, weaknesses, and planned remedies along with worthy projects for institutional improvement. The government reviews these institutional reports, along with external reviews, and provides supplemental funding to many projects, especially those involving modernizing facilities and improving services.
Program evaluation, based on external review, got underway in 1991, when the government established the Inter-institutional Committees for Higher Education Evaluation (CIEES). This program has now conducted some 250 external, peer-based "diagnostic" evaluations of academic programs at 66 institutions. Its work is organized into nine committees, covering different academic subject areas (each committee includes academics as well as representatives of employers, professional associations, and the government). In several professional fields, the work of these committees has led to the establishment of accreditation councils, some of which have already signed international recognition agreements for their programs.

Other initiatives have focused on assessing individuals, most specifically the research achievement and productivity of academic staff. Beginning in the 1980s, Mexico developed a National Researchers System (SNI), whereby individual academics are evaluated for their research productivity and given recognition as well as monetary rewards. This system, developed initially as a way to supplement the wages of highly productive academic staff, had an important early impact nationwide on Mexican higher education. More recently, programs are being developed to evaluate and recognize good teaching based on criteria and methods developed by academic committees within each institution. Here too, academics can be rewarded by financial bonuses for meeting certain performance standards.

Student achievement will also be subject to new efforts at assessment. A national evaluation center (CENEVAL) has been established with the long-term goal of developing and administering standardized examinations to test the knowledge and skills of students entering higher education. At present, however, CENEVAL administers its exams to senior high schools in the metropolitan area of Mexico City, while most public institutions still administer their own entrance examinations. CENEVAL is also developing examinations for university graduates in several professional areas.

\section{Programs are being developed to evalu- ate and recognize good teaching based on criteria and methods developed by academic committees within each insti- tution.}

While Mexico has made progress during the last decade, as in other countries involved in such reforms, the record is uneven, often based more on setting mechanisms in place than on institutional implementation. Nevertheless, concrete experience has been gained with different 
approaches, and some degree of acceptance has been achieved within the higher education sector. For example, private institutions have decided to develop an approach to assess quality. In 1993, the Mexican Federation of Private Institutions of Higher Education (FIMPES) adopted a strategy for operating its own system of self-evaluation with collectively approved criteria, indicators, and standards. Acceptance is reflected, too, in the readiness of higher education leaders to continue developing quality assurance. At its fall 1996 annual meeting, the National Association of Universities and Institutions of Higher Education (ANUIES), the major consensus-building organization for higher education, reiterated its commitment to the development of a coherent national system of quality assurance. ${ }^{2}$

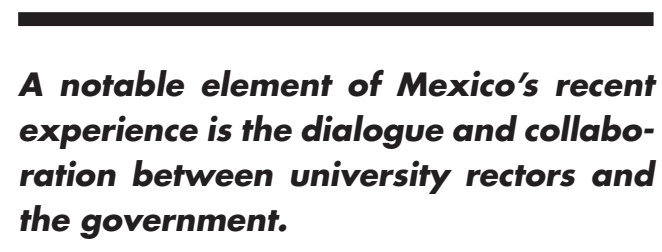

\section{Collaboration and Flexibility}

A notable element of Mexico's recent experience is the dialogue and collaboration between university rectors and the government. Rectors and government officials are represented in CONPES, the National Coordination for Higher Education Planning, which has, since 1979, been the major body charged with carrying out consultations on government initiatives and ways to implement national policies for higher education. Through CONPES, rectors supported the establishment of CONAEVA, the National Commission for the Evaluation of Higher Education. So too, ANUIES, the association of rectors, has participated in drawing up initiatives and guidelines for quality assessment procedures. In 1994, ANUIES was also instrumental in the creation of CENEVAL, the organization that is developing standardized examinations for students. Rectors of public universities have also played a role in CIEES by trying to resolve conflicts over the rejection of certain programs by the committees administering external evaluations.

Flexibility has also characterized Mexico's recent experience with quality assurance. Programs have gotten underway without a single approach being imposed on all institutions. Under the teaching careers program, for example, which evaluates academics for financial bonuses paid by the government, the specific criteria and methods for conducting the evaluations are drawn up by each institution. Institutional spokespersons acknowledge this flexibility, including, for example, several analysts who recently described the assessment system at UNAM as "complex, multidimensional, and versatile," combining both "tradition and innovation."

Flexibility is also evident in the area of institutional self-evaluation, for although CONAEVA issued general guidelines for preparing self-study reports, institutions were able to establish their own methods and follow-up procedures. A case in point is UAM, which as a decentralized university allowed each of the three units (campuses) to develop its own methods of self-evaluation. As a result, a single university has three different methodologies for conducting internal evaluation. ${ }^{4}$

Focused on program evaluation, the CIEES procedures have also been flexible. The evaluations began with a few academic areas, and expanded only after some experience was gained. So too, the program evaluations themselves are conducted only at the request of an institution.

To entice institutions to become involved in quality assessment, the government used a carrot-and-stick approach, offering financial incentives to institutions participating in the process. Since 1989, the government has allocated supplemental funds to public higher education institutions based, to some extent, on their annual self-assessments. Assessment procedures for individual academics, which can lead to increases in basic salaries by 100 to 200 percent, have helped to attract and retain qualified faculty and to maintain and improve faculty credentials, the volume of relevant research, and the overall quality of academic programs.

A substantial agenda lies ahead for Mexican higher education: it must respond to continuing expansion in demand as it also confronts significant and unsettling social and economic constraints. Its experience with quality assurance-following a flexible approach, building from experience, and listening to a range of voices-could prove to be a useful precedent for addressing other problems in the years ahead.

\section{Notes}

1. J. Brennan, Quality Assurance in Higher Education: An Overview (paper presented at the OECD/UNAM International Dissemination Conference on Quality Assessment in Higher Education, Mexico City, December 1-2, 1997).

2. S. Malo, Basic Information on Mexico's National Quality Assessment Agencies and Programs (paper presented at the OECD/ UNAM International Dissemination Conference on Quality Assessment in Higher Education, Mexico City, December 1-2, 1997).

3. L. Rojo, R. Seco, M. Martinez, and S. Malo, Quality Assessment and Decision-Making Processes at Mexico's National University (report presented at the OECD/UNAM/UAM Workshop on Institutional Experiences of Quality Assessment in Higher Education, Mexico City, November 28-29, 1997).

4. G. Valenti and G. Varela, The UAM Case Study (paper presented at the OECD/UNAM/UAM Workshop on Institutional Experiences of Quality Assessment in Higher Education, Mexico City, November 28-29, 1997). 